\title{
Diagnostics and treatment of diffuse intrinsic pontine glioma: where do we stand?
}

\author{
Fatma E. El-Khouly ${ }^{1,2,39}$. Sophie E. M. Veldhuijzen van Zanten ${ }^{1,2} \cdot$ Vicente Santa-Maria Lopez ${ }^{3}$. \\ N. Harry Hendrikse ${ }^{4,5} \cdot$ Gertjan J. L. Kaspers $^{1,2} \cdot$ G. Loizos $^{6} \cdot$ David Sumerauer $^{7} \cdot$ Karsten Nysom $^{8}$. \\ Kaie Pruunsild ${ }^{9}$. Virve Pentikainen ${ }^{10}$. Halldora K. Thorarinsdottir ${ }^{11}$. Giedre Rutkauskiene ${ }^{12} \cdot$ Victor Calvagna $^{13}$. \\ Monika Drogosiewicz ${ }^{14}$. Monica Dragomir ${ }^{15} \cdot$ Ladislav Deak $^{16} \cdot$ Lidija Kitanovski $^{17}$. Andre O. von Bueren ${ }^{18}$. \\ Rejin Kebudi $^{19}$ - Irene Slavc ${ }^{20}$. Sandra Jacobs ${ }^{21}$ • Filip Jadrijevic-Curlje ${ }^{22} \cdot$ Natacha Entz-Werle $^{23}$. \\ Jacques Grill ${ }^{24}$. Antonis Kattamis ${ }^{25}$. Peter Hauser ${ }^{26}$. Jane Pears ${ }^{27}$. Veronica Biassoni ${ }^{28} \cdot$ Maura Massimino $^{28}$. \\ Enrique Lopez Aguilar ${ }^{29} \cdot$ Ingrid K. Torsvik ${ }^{30}$. Maria Joao Gil-da-Costa ${ }^{31}$ - Ella Kumirova ${ }^{32}$ - Ofelia Cruz-Martinez ${ }^{3}$. \\ Stefan Holm ${ }^{33}$. Simon Bailey ${ }^{34}$. Tim Hayden ${ }^{35}$. Ulrich W. Thomale ${ }^{36}$. Geert O. R. Janssens ${ }^{37}$. Christof M. Kramm ${ }^{38}$. \\ Dannis G. van Vuurden ${ }^{1,2}$
}

Received: 16 July 2019 / Accepted: 5 September 2019 / Published online: 14 September 2019

(C) The Author(s) 2019

\begin{abstract}
Introduction Diffuse intrinsic pontine glioma (DIPG) is a rare clinically, neuro-radiologically, and molecularly defined malignancy of the brainstem with a median overall survival of approximately 11 months. Our aim is to evaluate the current tendency for its treatment in Europe in order to develop (inter)national consensus guidelines.

Methods Healthcare professionals specialized in DIPG were asked to fill in an online survey with questions regarding usual treatment strategies at diagnosis and at disease progression in their countries and/or their centers, respectively.

Results Seventy-four healthcare professionals responded to the survey, of which $87.8 \%$ were pediatric oncologists. Only $13.5 \%$ of the respondents biopsy all of their patients, $41.9 \%$ biopsy their patients infrequently. More than half of the respondents $(54.1 \%)$ treated their patients with radiotherapy only at diagnosis, whereas $44.6 \%$ preferred radiotherapy combined with chemotherapy. When the disease progresses, treatment strategies became even more diverse, and the tendency for no treatment increased from $1.4 \%$ at diagnosis to $77.0 \%$ after second progression. $36.5 \%$ of the healthcare professionals treat children younger than 3 years differently than older children at diagnosis. This percentage decreased, when the disease progresses. Most of the participants $(51.4 \%)$ included less than $25 \%$ of their patients in clinical trials.

Conclusion This survey demonstrates a large heterogeneity of treatment regimens, especially at disease progression. We emphasize the need for international consensus guidelines for the treatment of DIPG, possible by more collaborative clinical trials.
\end{abstract}

Keywords Diffuse intrinsic pontine glioma (DIPG) · Diffuse midline glioma H3-K27 mutant (DMG K3-27M) · Chemotherapy $\cdot$ Radiotherapy

Electronic supplementary material The online version of this article (https://doi.org/10.1007/s11060-019-03287-9) contains supplementary material, which is available to authorized users.

Fatma E. El-Khouly

f.el-khouly@amsterdamumc.nl

Extended author information available on the last page of the article

\section{Introduction}

Children suffering from diffuse intrinsic pontine glioma (DIPG) face a dismal prognosis with a median overall survival of approximately 11 months, and a 2 year survival rate of $10 \%[1,2]$. Due to the delicate location of the tumor, surgical resection is not possible. To date, radiotherapy remains standard of care at diagnosis and confers a survival benefit of approximately 3 months [3]. Chemotherapy has not proven to be effective thus far [2]. 
In the recently revised World Health Organization (WHO) classification of central nervous system (CNS) tumors, the majority of DIPG has neuropathologically been reclassified within a novel tumor entity: diffuse midline glioma, H3-K27 mutant (DMG H3-K27M). This entity is defined as an infiltrative high-grade glioma, located in the brain midline, i.e. usually brainstem, spinal cord, cerebellum or thalamus, with astrocytic differentiation and $\mathrm{K} 27 \mathrm{M}$ mutation in either H3F3A or HIST1H3B/C [4]. Up to 85\% of the DIPGs harbor this mutation [5, 6]. Wild-type H3-K27 DIPGs have not yet been separately classified within the revised WHO classification, but show similar survival as H3-K27M DIPGs [1, 7].

Because of the poor prognosis and limited effect of current treatment strategies, there are no (inter)national guidelines for both radio- and chemotherapy, resulting in a heterogeneous application of treatment schedules, as shown by a Dutch national inventory [8]. In this European retrospective study, we aim to evaluate the current tendency for treatment (i.e. the applied type of treatments per country, including enrollment in clinical trials) in a purpose to (i) structure optional inclusion in collaborative clinical trials, and (ii) stimulate the development of (inter)national consensus guidelines for the approach of DIPG patients.

\section{Methods}

An online survey was developed and distributed among healthcare professionals specialized in DIPG via the electronic mailing list of the International Society of Pediatric Oncology Europe Brain Tumor Group (SIOPE BTG; $n=414)$. The survey was published online via ThesisTools pro (www.thesistoolspro.com) and was open for participation for a total period of 10 weeks, from June 2018 to August 2018. Three weeks after the initial distribution the first reminder was sent, and after 6 weeks the second one.

The survey queried treatment regimens used in DIPG patients at diagnosis and at (first and subsequent) disease progression: initial treatment after diagnosis, second line treatment after first progression, and third line treatment after second progression. Participants were asked to describe the applied radiotherapy dose and fractionation, drugs, doses, and schedules, and whether patients participated in clinical trials or not. The full survey can be found in the supplementary material.

The data obtained from the survey were analyzed by descriptive statistical methods using IBM SPSS Statistics version 22 .

\section{Results}

Seventy-four health care professionals treating DIPG patients in Europe contributed to the online survey. Since this online survey was distributed via the electronic mailing list of the SIOPE BTG $(n=414)$, also including professionals not (directly) involved in the treatment of DIPG patients, and members of the SIOPE BTG group were asked to forward the survey to their colleagues outside the network who are also treating DIPG patients, it was not possible to determine the exact overall response rate.

Among the healthcare professionals who responded to the survey, $87.8 \%$ were pediatric oncologists. Others were radiation oncologists, pediatric neurosurgeons and child neurologists (Table 1). Most of the respondents (87.8\%) treat up to 5 patients per year (range 1-13 patients, with one outlier of 35 patients in Russia). Table 1 contains demographic data of the respondents.

\section{Biopsy and neuropathological diagnosis}

Most of the healthcare professionals (41.9\%) stated to biopsy their patients infrequently. Only $13.5 \%$ biopsy all DIPG patients, whereas $16.2 \%$ never biopsy DIPG patients (Table 2). 13.5\% of the healthcare professionals described to have difficulties in their daily routine with the new neuropathological diagnosis of DMG H3-K27M. A more detailed explanation of the experienced difficulties is the fact that biopsies are required to determine the neuropathological diagnosis, although explaining the potential relevance and benefit of a biopsy to patients and their families is particularly difficult as the result-in most cases-will not influence treatment decisions. $68.9 \%$ of the respondents stated to treat non-pontine DMG H3-K27M like they treat DIPG (i.e. radiotherapy only or radiotherapy combined with chemotherapy) versus $31.1 \%$ who treat them like they treat HGG (i.e. with radiotherapy combined with chemotherapy, mainly temozolomide).

\section{Treatment strategies}

$54.1 \%$ of the healthcare professionals considered radiotherapy as monotherapy to be standard of care at diagnosis (Table 3). Of these, $47.5 \%$ use conventionally-fractionated radiotherapy (54-60 Gy in 1.8-2.0 Gy fractions) versus $17.5 \%$ who prescribe a biologically equivalent hypo-fractionated dose of $30-40$ Gy in 3.0-4.0 Gy fractions. 35\% of respondents indicated that they give both conventionallyand hypo-fractionated radiotherapy to their DIPG patients. $44.6 \%$ of the respondents considered radiotherapy combined with chemotherapy standard of care at diagnosis, of which $39.4 \%$ combine radiotherapy with daily temozolomide, and 
Table 1 Demographic data of the healthcare professionals treating DIPG patients who contributed to the online survey

\begin{tabular}{|c|c|}
\hline & $\mathrm{n}=74(\%)$ \\
\hline \multicolumn{2}{|l|}{ Function/specialty } \\
\hline Pediatric oncologist & $65(87.8)$ \\
\hline Radiation oncologist & $1(1.4)$ \\
\hline Pediatric neurosurgeon & $5(6.8)$ \\
\hline Child neurologist & $3(4.1)$ \\
\hline DIPG national coordinator ${ }^{\mathrm{a}}$ & $15(20.3)$ \\
\hline DIPG trial coordinator & 13 (17.6) \\
\hline \multicolumn{2}{|c|}{ Number of DIPG patients treated per year } \\
\hline $0-5$ & $65(87.8)$ \\
\hline $6-10$ & $7(9.5)$ \\
\hline $11-15$ & $1(1.4)$ \\
\hline$>15$ & $1(1.4)$ \\
\hline \multicolumn{2}{|l|}{ Country } \\
\hline Netherlands & $8(10.8)$ \\
\hline Germany & $4(5.4)$ \\
\hline Spain & 11 (14.9) \\
\hline Italy & $5(6.8)$ \\
\hline Belgium & $5(6.8)$ \\
\hline France & $8(10.8)$ \\
\hline United Kingdom & $11(14.9)$ \\
\hline Switzerland & $3(4.1)$ \\
\hline Sweden & $1(1.4)$ \\
\hline Norway & $2(2.7)$ \\
\hline Portugal & $1(1.4)$ \\
\hline Russia & $2(2.7)$ \\
\hline Slovakia & $2(2.7)$ \\
\hline Slovenia & $1(1.4)$ \\
\hline Lithuania & $1(1.4)$ \\
\hline Hungary & $1(1.4)$ \\
\hline Greece & $2(2.7)$ \\
\hline Croatia & $1(1.4)$ \\
\hline Czech Republic & $1(1.4)$ \\
\hline Denmark & $1(1.4)$ \\
\hline Austria & $2(2.7)$ \\
\hline Australia & $1(1.4)$ \\
\hline
\end{tabular}

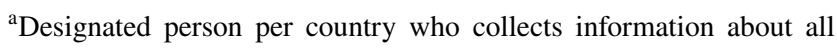
DIPG patients for the European DIPG registry

Table 2 Frequency of biopsy in DIPG patients

\begin{tabular}{ll}
\hline & $\mathrm{n}=74(\%)$ \\
\hline All patients & $10(13.5)$ \\
Most patients & $21(28.4)$ \\
Few patients & $31(41.9)$ \\
Never & $12(16.2)$ \\
\hline
\end{tabular}

Table 3 Provided first line therapy to DIPG patients by responding healthcare professionals

\begin{tabular}{lr}
\hline & $\mathrm{n}=74(\%)$ \\
\hline Radiotherapy only & $\mathbf{4 0}(\mathbf{5 4 . 1})$ \\
CF RTx & $19(47.5)$ \\
HF RTx & $7(17.5)$ \\
CF RTx or HF RTx & $14(35.0)$ \\
Radiotherapy combined with chemotherapy & $\mathbf{3 3}(\mathbf{4 4 . 6})$ \\
CF RTx + temozolomide & $13(39.4)$ \\
CF RTx + nimotuzumab + vinorelbine & $6(18.2)$ \\
CF RTx + other chemotherapeutics & $14(42.4)$ \\
No treatment & $\mathbf{1}(\mathbf{1 . 4})$ \\
\hline
\end{tabular}

CF RTx Conventionally fractionated radiotherapy, 54-60 Gy in 1.82.0 Gy fractions, HF RTx Hypo-fractionated radiotherapy, 30-40 Gy in 3.0-4.0 Gy fractions

Table 4 Provided second and third line therapy to DIPG patients (after first and second progression) by responding healthcare professionals

\begin{tabular}{lr}
\hline & $\mathrm{n}=74(\%)$ \\
\hline Second line therapy & \\
HF radiotherapy only & $40(54.1)$ \\
HF radiotherapy + chemotherapy & $17(23.0)$ \\
Chemotherapy only & $6(8.1)$ \\
Immunotherapy & $2(2.7)$ \\
No treatment & $7(9.5)$ \\
Other & $2(2.7)$ \\
Third line therapy & $8(10.8)$ \\
HF Radiotherapy ${ }^{\mathrm{a}}$ only & $5(6.8)$ \\
Chemotherapy only & $3(4.1)$ \\
HF Radiotherapy ${ }^{\mathrm{a}}+$ chemotherapy & $1(1.4)$ \\
Immunotherapy & $57(77.0)$ \\
No treatment & Gy in 3.0- \\
\hline HF radiotherapy hypo-fractionated radiotherapy, $30-40$ & \\
4.0 Gy fractions) &
\end{tabular}

$60.6 \%$ use other concomitant chemotherapy. Chemotherapy was only given together with a conventionally fractionated radiotherapy scheme.

At first progression, $77.0 \%$ of the healthcare professionals considered re-irradiation to be standard of second-line care; $70.2 \%$ of these use re-irradiation only, and $29.8 \% \mathrm{com}$ bine re-irradiation with chemotherapy. Others described to use chemotherapy only, immunotherapy, or no treatment at all. At second progression (third line therapy), $77.0 \%$ of the respondents did not actively treat their patients and provided only palliative symptom control. Others stated to use several treatment strategies (Table 4).

$36.5 \%$ of the respondents stated to treat children younger than 3 years at diagnosis different than older children; 
starting with no treatment or chemotherapy only, instead of radiotherapy. The percentage of caregivers giving a different treatment decreased when the disease progressed, to $23.0 \%$ after first and $13.5 \%$ after second progression, respectively.

\section{Participation in clinical trials}

Seventy-three percent of the healthcare professionals reported to have ongoing clinical trials in their hospital or another referable center in their country. $51.4 \%$ of the respondents stated that less than $25 \%$ of their patients participate in ongoing clinical trials (Table 5).

\section{Discussion}

Regular exposure to larger numbers of DIPG patients remains low; up to $90 \%$ of the healthcare professionals treat less than five DIPG patients per year. This study confirms the need for more (inter)national collaboration to increase knowledge about the disease and reasonable treatment strategies.

Over the past 20 years, neuropathological diagnosis of tumors arising in the pons has been subject to change. In the late 90s, performing biopsies in children suffering from DIPG was not recommended because of the presumed risk of the biopsy procedures, and because of the fact that histological grading did not alter therapy outcome $[9,10]$. This paradigm slowly shifted when reports showing the safety of biopsies were published [11]. In 2011, a multi-disciplinary consensus statement was published justifying biopsies as part of clinical trials to investigate tumor grading and biological markers important for treatment selection [12]. In 2015 , German colleagues performed a smaller scale $(n=18)$ email survey, similar to ours, also within the SIOPE DIPG network, which demonstrated that at that time approximately $10 \%$ of the healthcare professionals biopsied their patients (prof. C.M. Kramm, unpublished data). The results of our study show an increase; currently $42 \%$ of the healthcare professionals state to biopsy all or most of their patients, compared to $16 \%$ who never biopsy their patients. This

Table 5 Number of healthcare professionals who include patients in clinical trials

\begin{tabular}{lr}
\hline & $\mathrm{n}=74(\%)$ \\
\hline $\begin{array}{l}\text { Patients participating in clinical trials } \\
<25 \%\end{array}$ & $38(51.4)$ \\
$25-50 \%$ & $8(10.8)$ \\
$50-75 \%$ & $6(8.1)$ \\
$>75 \%$ & $22(29.7)$ \\
No clinical trials in center or nearby & $20(27.0)$ \\
\hline
\end{tabular}

paradigm shift towards integrating biopsies in the work-up of DIPG patients could be explained by the increase of clinical trials over the years. Trials such as BIOMEDE with treatment decisions according to the molecular findings within performed biopsies, could be the main drivers behind this trend. Especially since our results show that healthcare professionals are reluctant to have an invasive procedure like a biopsy performed in DIPG patients, when it does not provide a benefit or therapeutic consequence.

This international survey study demonstrates that almost all DIPG patients are treated with radiotherapy at diagnosis, either alone $(54.1 \%)$ or combined with chemotherapy (44.6\%). In a Dutch cohort study covering 1990-2010, $79.6 \%$ of the DIPG patients were treated with radiotherapy at diagnosis, of whom $66 \%$ received radiotherapy alone, and $13.6 \%$ received radiotherapy combined with chemotherapy [8]. The observed modest shift towards combining radiotherapy with chemotherapy in our current study might, like the tendency to biopsy, be explained by the increased of the number of available clinical trials over the past decade.

Of the radiotherapy schedules, most healthcare professionals apply conventionally-fractionated radiotherapy at diagnosis, especially when patients participate in clinical trials. Our study shows that outside clinical trials some healthcare professionals tend to use hypo-fractionated radiotherapy because of its lower-burden regimen and as conventionallyor hypo-fractionated radiotherapy schedules in DIPG have been shown to result in equal overall survival rates [13].

Heterogeneity in treatment is demonstrated, especially when the disease progresses. Among all treatments given, re-irradiation (either alone or combined with chemotherapy) is mostly used after first progression, and has been proven to give a significant survival benefit of 3.4 months in DIPG patients [14]. At further progressions, treatment strategies such as chemotherapy alone or immunotherapy are also used. However, these numbers are low and are especially in case of chemotherapy mostly related to participation in clinical trials. After second progression, $77 \%$ of the healthcare professionals do not actively treat their patients, which is in line with previously published work within one country by Veldhuijzen van Zanten et al. [15]. Healthcare professionals prefer to provide palliative and end-of-life care in this last stage of the disease.

Looking at age-related differences in treatment, our study shows that $74.5 \%$ of the healthcare professionals treat children younger than three years the same as older children, whereas previous studies have shown that younger age at diagnosis is correlated to longer survival of DIPG patients $[2,16]$. A possible explanation for this attitude, despite the significantly better prognosis of infant DIPG patients, might be because infant DIPGs are extremely rare and, therefore, the potentially better prognosis which can often be reached with chemotherapy alone, might not be general knowledge 
and/or accepted yet. The percentage of healthcare professionals who treat younger children different than older children decreases when the disease progresses because with progression the possible advantage of infant DIPG patients with regards to a potential better prognosis has obviously vanished. This is in line with the transition from active treatment to palliative and end-of-life care, which is less age dependent.

As mentioned before, the increased availability of clinical trials and increased knowledge on the biological background of DIPG over the past decades could explain the actual trend towards biopsies and the different treatment combinations (e.g. radiotherapy combined with chemotherapy). Our study, however, demonstrates that participation in clinical trials still remains low; more than half of the healthcare professionals include less than $25 \%$ of their patients in clinical trials. This is in agreement with the results of a previous study by van der Geest et al., who investigated participation in clinical trials of children with incurable cancers. They demonstrated that less than one-third of the patients participate in a clinical trial [17], which might be explained by (i) the ethical dilemma's health care professionals face regarding mandatory parts of the trials, i.e. biopsies with no direct benefit for the patient; (ii) the travel distance to a study center, resulting in parents declining participation in the trial; and (iii) cultural differences. To illustrate, in some countries, parents/patients do not want to do anything but palliative care to minimize a child's suffering, while in other countries parents/patients are willing to do everything to get any form of treatment. The latter is exemplified by the increased crowdfunding events over the past years, where parents raise money to participate in clinical trials abroad. This will add to the responsibilities of healthcare professionals, who have to help parents balancing between the benefits of participation in clinical trials and preserving the child's needs and protect them from unnecessary treatment burden. For this purpose, we advocate more collaboration between countries, with the aim to bring clinical trials to the patients, instead of the patients to the trials. To do so, international disease networks and registries, such as the SIOPE DIPG network and the SIOPE DIPG Registry, could be the foundation of collaborative trials [18].

Our study again confirms the heterogeneity of the treatment of DIPG, on a European level. To date, there are still no guidelines for both chemo- and radiotherapy, resulting in a wide variety of treatment schedules, especially at disease progression. This research therefore calls for international (SIOPE) guidelines and/or treatment recommendations with patient outcome data registration via the DIOPE DIPG Registry. Putting our data in perspective of the past twenty years, our results show less heterogeneity over time; fewer treatment strategies are considered at diagnosis and progression. More collaboration on a European level and working together on clinical trials is recommended to combine international expertise and to work towards collaborative clinical trials with higher patient numbers and, hopefully, to achieve quicker results. This cooperation is the basis for trying to change the dismal prognosis of patients suffering from DIPG.

Acknowledgements We would also like to thank all respondents for their contribution by filling in the online survey.

Author contributions All authors contributed to the study conception and design. Material preparation, data collection and analysis were performed by FEE-K, SEMVZ, VS-ML, DGV and CMK. The first draft of the manuscript was written by FEE-K and all authors commented on previous versions of the manuscript. All authors read and approved the final manuscript.

Funding DIPG research in Amsterdam UMC, location VUmc is financially supported by the Semmy Foundation (Stichting Semmy). DIPG research at the University Medical Center Goettingen is supported by the Deutsche Kinderkrebsstiftung, Bonn, Germany, and Menschen fuer Kinder e.V., Albshausen, Germany.

\section{Compliance with ethical standards}

Conflict of interest The authors declare that they have no conflict of interest.

Open Access This article is distributed under the terms of the Creative Commons Attribution 4.0 International License (http://creativeco mmons.org/licenses/by/4.0/), which permits unrestricted use, distribution, and reproduction in any medium, provided you give appropriate credit to the original author(s) and the source, provide a link to the Creative Commons license, and indicate if changes were made.

\section{References}

1. Hoffman LM, Veldhuijzen van Zanten SEM, Colditz N, Baugh J, Chaney B, Hoffmann M, Lane A, Fuller C, Miles L, Hawkins C, Bartels U, Bouffet E, Goldman S, Leary SN, Foreman NK, Packer R, Warren KE, Broniscer A, Kieran MW, Minturn J, Comito M, Broxson E, Shih C, Khatua S, Chintagumpala M, Carret AS, Escorza NY, Hassall T, Ziegler DS, Gottardo N, Dholaria H, Doughman R, Benesch M, Drissi R, Nazarian J, Jabado N, Boddaert N, Varlet P, Giraud G, Castel D, Puget S, Jones C, Hulleman E, Modena P, Giagnacovo M, Antonelli M, Pietsch T, Gielen GH, Jones DTW, Sturm D, Pfister SM, Gerber NU, Grotzer MA, Pfaff E, von Bueren A, Hargrave D, Solanki GA, Jadrijevic Cvrlje F, Kaspers GJL, Vandertop WP, Grill J, Bailey S, Biassoni V, Massimino M, Calmon R, Sanchez E, Bison B, Warmuth-Metz M, Leach J, Jones B, van Vuurden DG, Kramm CM, Fouladi M (2018) Clinical, radiologic, pathologic, and molecular characteristics of long-term survivors of diffuse intrinsic pontine glioma (DIPG): A Collaborative Report From the International and European Society for Pediatric Oncology DIPG Registries. J Clin Oncol 36(19):1963-1972. https://doi.org/10.1200/JCO10 $.1200 / \mathrm{JCO} .2017$

2. Jansen MH, Veldhuijzen van Zanten SE, Sanchez Aliaga E, Heymans MW, Warmuth-Metz M, Hargrave D, van der Hoeven EJ, Gidding CE, de Bont ES, Eshghi OS, Reddingius R, Peeters CM, Schouten-van Meeteren AY, Gooskens RH, Granzen B, 
Paardekooper GM, Janssens GO, Noske DP, Barkhof F, Kramm CM, Vandertop WP, Kaspers GJ, van Vuurden DG (2015) Survival prediction model of children with diffuse intrinsic pontine glioma based on clinical and radiological criteria. Neuro Oncol 17(1):160-166. https://doi.org/10.1093/neuonc/nou104

3. Langmoen IA, Lundar T, Storm-Mathisen I, Lie SO, Hovind KH (1991) Management of pediatric pontine gliomas. Childs Nerv Syst 7(1):13-15

4. Louis DN, Perry A, Reifenberger G, von Deimling A, FigarellaBranger D, Cavenee WK, Ohgaki H, Wiestler OD, Kleihues P, Ellison DW (2016) The 2016 World Health Organization Classification of Tumors of the Central Nervous System: a summary. Acta Neuropathol 131(6):803-820. https://doi.org/10.1007/s0040 1-016-1545-1

5. Castel D, Philippe C, Calmon R, Le Dret L, Truffaux N, Boddaert N, Pages M, Taylor KR, Saulnier P, Lacroix L, Mackay A, Jones C, Sainte-Rose C, Blauwblomme T, Andreiuolo F, Puget S, Grill J, Varlet P, Debily MA (2015) Histone H3F3A and HIST1H3B K27M mutations define two subgroups of diffuse intrinsic pontine gliomas with different prognosis and phenotypes. Acta Neuropathol 130(6):815-827. https://doi.org/10.1007/s0040 1-015-1478-0

6. Karremann M, Gielen GH, Hoffmann M, Wiese M, Colditz N, Warmuth-Metz M, Bison B, Claviez A, van Vuurden DG, von Bueren AO, Gessi M, Kuhnle I, Hans VH, Benesch M, Sturm D, Kortmann RD, Waha A, Pietsch T, Kramm CM (2018) Diffuse high-grade gliomas with $\mathrm{H} 3 \mathrm{~K} 27 \mathrm{M}$ mutations carry a dismal prognosis independent of tumor location. Neuro Oncol 20(1):123-131. https://doi.org/10.1093/neuonc/nox149

7. von Bueren AO, Karremann M, Gielen GH, Benesch M, Fouladi M, van Vuurden DG, van Zanten S, Hoffman LM, Kramm CM (2018) A suggestion to introduce the diagnosis of "diffuse midline glioma of the pons, H3 K27 wildtype (WHO grade IV)". Acta Neuropathol 136(1):171-173. https://doi.org/10.1007/s0040 1-018-1863-6

8. Veldhuijzen van Zanten SE, Jansen MH, Sanchez Aliaga E, van Vuurden DG, Vandertop WP, Kaspers GJ (2015) A twenty-year review of diagnosing and treating children with diffuse intrinsic pontine glioma in the Netherlands. Expert Rev Anticancer Ther 15(2):157-164. https://doi.org/10.1586/14737140.2015.974563

9. Cartmill M, Punt J (1999) Diffuse brain stem glioma A review of stereotactic biopsies. Childs Nerv Syst 15(5):235-237 discussion 238

10. Dellaretti M, Reyns N, Touzet G, Dubois F, Gusmão S, Pereira JLB, Blond S (2012) Diffuse brainstem glioma: prognostic factors. J Neurosurg 117(5):810-814. https://doi. org/10.3171/2012.7.JNS111992

11. Hamisch C, Kickingereder P, Fischer M, Simon T, Ruge MI (2017) Update on the diagnostic value and safety of stereotactic biopsy for pediatric brainstem tumors: a systematic review and meta-analysis of 735 cases. J Neurosurg 20(3):261-268. https:// doi.org/10.3171/2017.2.PEDS1665

12. Walker DA, Liu J, Kieran M, Jabado N, Picton S, Packer R, St Rose C, Group CPNPCC (2013) A multi-disciplinary consensus statement concerning surgical approaches to low-grade, highgrade astrocytomas and diffuse intrinsic pontine gliomas in childhood (CPN Paris 2011) using the Delphi method. Neuro Oncol 15(4):462-468. https://doi.org/10.1093/neuonc/nos330
13. Janssens GO, Jansen MH, Lauwers SJ, Nowak PJ, Oldenburger FR, Bouffet E, Saran F, Kamphuis-van Ulzen K, van Lindert EJ, Schieving JH, Boterberg T, Kaspers GJ, Span PN, Kaanders JH, Gidding CE, Hargrave D (2013) Hypofractionation vs conventional radiation therapy for newly diagnosed diffuse intrinsic pontine glioma: a matched-cohort analysis. Int J Radiat Oncol Biol Phys 85(2):315-320. https://doi.org/10.1016/j.ijrobp.2012.04.006

14. Janssens GO, Gandola L, Bolle S, Mandeville H, Ramos-Albiac M, van Beek K, Benghiat H, Hoeben B, Morales La Madrid A, Kortmann RD, Hargrave D, Menten J, Pecori E, Biassoni V, von Bueren AO, van Vuurden DG, Massimino M, Sturm D, Peters M, Kramm CM (2017) Survival benefit for patients with diffuse intrinsic pontine glioma (DIPG) undergoing re-irradiation at first progression: a matched-cohort analysis on behalf of the SIOP-EHGG/DIPG working group. Eur J Cancer 73:38-47. https://doi. org/10.1016/j.ejca.2016.12.007

15. Veldhuijzen van Zanten SE, van Meerwijk CL, Jansen MH, Twisk JW, Anderson AK, Coombes L, Breen M, Hargrave OJ, Hemsley J, Craig F, Cruz O, Kaspers GJ, van Vuurden DG, Hargrave DR, Network SD (2016) Palliative and end-of-life care for children with diffuse intrinsic pontine glioma: results from a London cohort study and international survey. Neuro Oncol 18(4):582588. https://doi.org/10.1093/neuonc/nov250

16. Broniscer A, Laningham FH, Sanders RP, Kun LE, Ellison DW, Gajjar A (2008) Young age may predict a better outcome for children with diffuse pontine glioma. Cancer 113(3):566-572. https ://doi.org/10.1002/cncr.23584

17. van der Geest IM, van den Heuvel-Eibrink MM, Zwaan CM, Pieters R, Passchier J, Darlington AS (2016) Participation in a clinical trial for a child with cancer is burdensome for a minority of children. Acta Paediatr 105(9):1100-1104. https://doi.org/10.1111/ apa. 13405

18. Veldhuijzen van Zanten SE, Baugh J, Chaney B, De Jongh D, Sanchez Aliaga E, Barkhof F, Noltes J, De Wolf R, Van Dijk J, Cannarozzo A, Damen-Korbijn CM, Lieverst JA, Colditz N, Hoffmann M, Warmuth-Metz M, Bison B, Jones DT, Sturm D, Gielen GH, Jones C, Hulleman E, Calmon R, Castel D, Varlet P, Giraud G, Slave I, Van Gool S, Jacobs S, Jadrijevic-Cvrlje F, Sumerauer D, Nysom K, Pentikainen V, Kivivuori SM, Leblond P, EntzWerle N, von Bueren AO, Kattamis A, Hargrave DR, Hauser P, Garami M, Thorarinsdottir HK, Pears J, Gandola L, Rutkauskiene G, Janssens GO, Torsvik IK, Perek-Polnik M, Gil-da-Costa MJ, Zheludkova O, Shats L, Deak L, Kitanovski L, Cruz O, Morales La Madrid A, Holm S, Gerber N, Kebudi R, Grundy R, LopezAguilar E, Zapata-Tarres M, Emmerik J, Hayden T, Bailey S, Biassoni V, Massimino M, Grill J, Vandertop WP, Kaspers GJ, Fouladi M, Kramm CM, van Vuurden DG, members of the SDN (2017) Development of the SIOPE DIPG network, registry and imaging repository: a collaborative effort to optimize research into a rare and lethal disease. J Neurooncol. https://doi.org/10.1007/ s11060-016-2363-y

Publisher's Note Springer Nature remains neutral with regard to jurisdictional claims in published maps and institutional affiliations. 


\section{Affiliations}

Fatma E. El-Khouly ${ }^{1,2,39}$. Sophie E. M. Veldhuijzen van Zanten ${ }^{1,2}$. Vicente Santa-Maria Lopez ${ }^{3}$. N. Harry Hendrikse ${ }^{4,5} \cdot$ Gertjan J. L. Kaspers $^{1,2} \cdot$ G. Loizos $^{6} \cdot$ David Sumerauer $^{7} \cdot$ Karsten Nysom $^{8}$. Kaie Pruunsild ${ }^{9}$. Virve Pentikainen ${ }^{10}$. Halldora K. Thorarinsdottir ${ }^{11}$. Giedre Rutkauskiene ${ }^{12} \cdot$ Victor Calvagna $^{13}$. Monika Drogosiewicz ${ }^{14}$. Monica Dragomir ${ }^{15}$. Ladislav Deak ${ }^{16}$. Lidija Kitanovski ${ }^{17}$. Andre O. von Bueren ${ }^{18}$. Rejin Kebudi $^{19}$. Irene Slavc ${ }^{20}$ - Sandra Jacobs ${ }^{21}$ - Filip Jadrijevic-Curlje ${ }^{22}$ - Natacha Entz-Werle ${ }^{23}$. Jacques Grill ${ }^{24}$ - Antonis Kattamis ${ }^{25}$. Peter Hauser ${ }^{26}$. Jane Pears ${ }^{27}$. Veronica Biassoni ${ }^{28}$. Maura Massimino ${ }^{28}$. Enrique Lopez Aguilar ${ }^{29} \cdot$ Ingrid K. Torsvik ${ }^{30}$ - Maria Joao Gil-da-Costa ${ }^{31}$ - Ella Kumirova ${ }^{32}$ - Ofelia Cruz-Martinez ${ }^{3}$. Stefan Holm ${ }^{33}$. Simon Bailey ${ }^{34}$. Tim Hayden ${ }^{35}$. Ulrich W. Thomale ${ }^{36}$. Geert O. R. Janssens ${ }^{37}$. Christof M. Kramm ${ }^{38}$. Dannis G. van Vuurden ${ }^{1,2}$

1 Pediatric Oncology, Emma Children's Hospital, Amsterdam UMC, Vrije Universiteit Amsterdam, Amsterdam, The Netherlands

2 Princess Máxima Center for Pediatric Oncology, Utrecht, The Netherlands

3 Department of Pediatric Hematology, Oncology and Stem Cell Transplantation, St Joan de Déu Children's Hospital, Barcelona, Spain

4 Department of Clinical Pharmacology \& Pharmacy, Amsterdam UMC, Vrije Universiteit Amsterdam, Amsterdam, The Netherlands

5 Department of Radiology \& Nuclear Medicine, Amsterdam UMC, Vrije Universiteit Amsterdam, Amsterdam, The Netherlands

6 Pediatric Oncology-Hematology Clinic, Archbishop Makarios III Hospital, Nicosia, Cyprus

7 Department of Pediatric Hematology and Oncology, 2nd Faculty of Medicine, University Hospital Motol, Charles University, Prague, Czech Republic

8 Pediatrics and Adolescent Medicine, University Hospital Rigshospitalet, Copenhagen, Denmark

9 Department of Hematology and Oncology, Tallinn Children's Hospital, Tallinn, Estonia

10 Division of Hematology-Oncology and Stem Cell Transplantation, Children's Hospital, Helsinki University Hospital, Helsinki, Finland

11 Pediatric Hematology-Oncology, The Children's Hospital, Reykjavík, Iceland

12 Department of Pediatric Oncology and Hematology, Hospital of Lithuanian University of Health Sciences Kaunas Clinic, Kaunas, Lithuania

13 Mater Dei Hospital, Valletta, Malta

14 Children's Memorial Health Institute, Warsaw, Poland

15 Department of Pediatric Oncology, Oncology Institute Professor Doctor Alexandru Trestioreanu, Bucharest, Romania

16 Department of Pediatric Oncology/Hematology, Children University Hospital, Kosice, Slovakia

17 Division of Hemato-Oncology, Department of Pediatrics, University Medical Center Ljubljana, Ljubljana, Slovenia
18 Pediatric Oncology and Hematology, Department of Pediatrics, University Hospital of Geneva, Geneva, Switzerland

19 Pediatric Hematology-Oncology, Cerrahpasa Medical Faculty \& Oncology Institute, Istanbul University, Istanbul, Turkey

20 Department of Pediatrics and Adolescent Medicine, Medical University of Vienna, Vienna, Austria

21 Universitair Ziekenhuis Leuven, Leuven, Belgium

22 Department of Oncology and Hematology, Children's Hospital Zagreb, Zagreb, Croatia

23 CHRU Hautepierre Strasbourg, Service de Pédiatrie Onco-Hématologie, Strasbourg, France

24 Département de Cancérologie de l'enfant et de l'adoloscent, CLCC Institut Gustave Roussy, Villejuif, France

25 First Department of Pediatrics, 'Aghia Sofia' Children's Hospital, National and Kapodistrian University of Athens, Athens, Greece

26 Second Department of Pediatrics, Semmelweis University, Budapest, Hungary

27 Department of Pediatric Oncology, Our Lady's Children's Hospital, Crumlin, Dublin, Ireland

28 Pediatric Oncology Unit, Fondazione IRCCS Istituto Nazionale dei Tumori, Milan, Italy

29 Hospital de Pediatría, Centro Médico National Siglo XXI, Instituto Mexicano del Seguro Social, Jefatura de Servicio de Oncologia, Distrito Federal, Mexico

30 Division of Oncology/Hematology, Department of Pediatrics, Haukeland University Hospital, Mons, Norway

31 Pediatric Hematology and Oncology Division, University Hospital S. João Alameda Hernani Monteiro, Porto, Portugal

32 Department of Neurooncology, Federal Research and Clinical Centre of Pediatric Hematology, Oncology and Immunology (FRC-PHOI), Moscow, Russia

33 Department of Pediatric Hematology and Oncology, Department of Woman and Child Health, Karolinska University Hospital, Stockholm, Sweden

34 Great North Children's Hospital, Victoria Wing, Royal Victoria Infirmary, Newcastle upon Tyne, UK

35 The DIPG Collaborative, Cincinnati, USA 
36 Pediatric Neurosurgery, Charité University Medical Center Berlin, Berlin, Germany

37 Department of Radiation Oncology, University Medical Center Utrecht, Utrecht, The Netherlands

38 Division of Pediatric Hematology and Oncology, University Medical Center Geottingen, Göttingen, Germany
39 Department of Pediatric Oncology/Hematology, Amsterdam UMC, location VUmc, De Boelelaan 1117, 1081 HV Amsterdam, The Netherlands 